\title{
Serum and intracellular retinol transport in the equine
}

\author{
BY D. SKLAN \\ Faculty of Agriculture, The Hebrew University of Jerusalem, Rehovot, Israel \\ AND SUSAN DONOGHUE* \\ Department of Clinical Studies, New Bolton Center, University of Pennsylvania, \\ Kennett Square, Pennsylvania 19348, USA
}

(Received 12 May 1981-Accepted 21 September 1981)

\begin{abstract}
1. Serum and intracellular distribution of retinol was determined in equines maintained on four levels of vitamin A intake.

2. The form of retinol transported in serum was determined by gel filtration and chromatography to be a complex of retinol bound to a protein of molecular weight (MW) of approximately 20000 , which was in turn complexed probably with prealbumin to yield a complex with a MW of 75000 to 80000 .

3. Increasing dietary vitamin A levels enhanced the concentration of lipoprotein-bound retinyl esters in the plasma.

4. Vitamin $\mathbf{A}$ in the liver cytosol was found predominantly as retinyl esters in a lipid-protein aggregate of $\mathrm{MW}$ approximately $2 \times 10^{6}$ and hydrated density of $1.063-1 \cdot 111$. In the kidney and adrenal gland, two lipid-protein entitites were found with MW of approximately $1.8 \times 10^{6}$ and $1.7 \times 10^{5}$ respectively. These fractions contained approximately 40 and $20 \%$ lipid respectively and had densities of $1 \cdot 063-1 \cdot 111$ and approximately $1 \cdot 21$.

5. All lipid-protein aggregates were associated with retinyl palmitate hydrolase activity and guanidine treatment released a $15000 \mathrm{MW}$ material, presumably intracellular retinol-binding protein.

6. Increasing dietary vitamin A enhanced the proportion of retinol in the $1.7 \times 10^{5}$ fraction.

7. Findings in equine plasma and liver resemble previous observations in other species. The characterization of two new lipid-protein aggregates in equine kidney and adrenal glands, which have hydrolase activity, may be important in intracellular retinol transport and metabolism, especially in animals subjected to high intakes of vitamin A.
\end{abstract}

Liver contains the major stores of vitamin A in mammals, and this is usually in the form of retinyl esters. Hepatic retinyl esters are hydrolysed to retinol which becomes complexed to a specific carrier, retinol binding protein (RBP), of molecular weight (MW) approximately 20000 before release to the blood. A further complexation to prealbumin then occurs and in this form retinol is transported to tissues (Smith \& Goodman, 1979). RBP does not appear to cross tissue membranes and an intracellular binding protein, which differs in MW (14600) and immunologically from RBP has been isolated from cytosol (Ong \& Chytil, 1978, Ross et al. 1978). A lipid-protein aggregate contains the majority of the retinyl esters in rat eye (Heller, 1976) and liver cytosol (Heller, 1979). It is associated with retinyl palmitate hydrolase activity (Chen \& Heller, 1979).

Little is known concerning retinol transport systems in the equine. In a recent study (Donoghue et al. 1981), the equine appeared to be particularly susceptible to abnormal intakes of vitamin A with significant changes in growth, haematology and serum biochemistries before development of clinical signs. These findings indicate the possibility that retinol transport systems may be affected by abnormal vitamin $\mathrm{A}$ intakes, and elucidation of these transport systems in the equine was the object of the present study. 
Table 1. Composition $(\mathrm{g} / \mathrm{kg})$ of the low-carotene diet

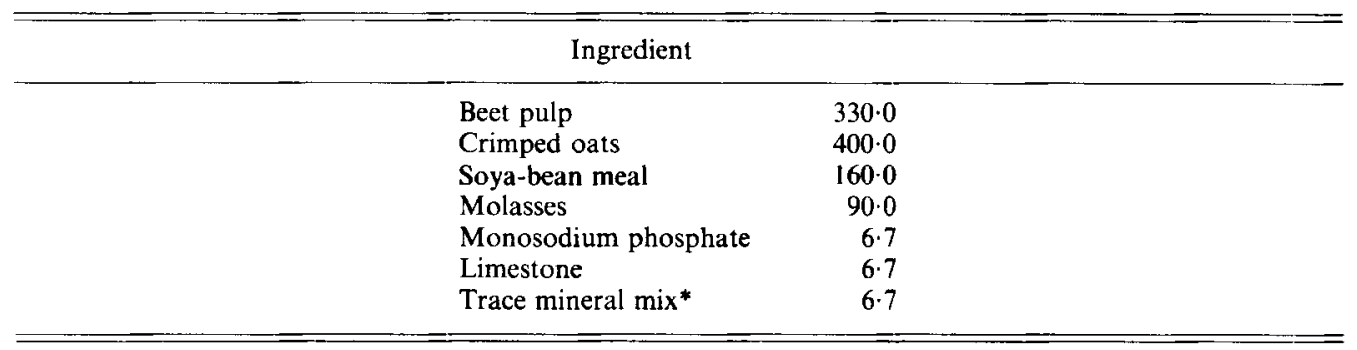

* Contained $(\mathrm{g}): 6.3$ sodium chloride, 0.0335 zinc, 0.0268 manganese, 0.0168 iron, 0.0036 copper, 0.0007 iodine and 0.007 cobalt; cholecalciferol was added at $21 \cdot 1 \mu \mathrm{g}$.

EXPERIMENTAL

Animals and diets. Fifteen horse and pony fillies less than 18 months old were housed and managed essentially as described previously (Donoghue et al. 1981). Fillies were given a vitamin A-free low-carotene diet (Table 1) in amounts equal to $30 \mathrm{~g} / \mathrm{kg}$ body-weight per d. Following accommodation and standardization, fillies were grouped randomly according to age and size into four groups receiving retinyl proprionate daily equivalent to 0 (four fillies; mildly deficient), 12 (three fillies; control group), 1200 (four fillies; mildly intoxicated group) and 12000 (four fillies; severely intoxicated group) $\mu \mathrm{g}$ retinol $/ \mathrm{kg}$ body-weight. This supplement was diluted in maize oil and administered orally.

Fillies were weighed and blood sampled monthly. After 40 weeks, fillies were killed by an intravenous injection of sodium pentobarbitol. Livers, kidneys and adrenal glands were removed, weighed and frozen at $-20^{\circ}$ until analysed.

Results of the monthly blood analyses and post-mortem examination will be reported elsewhere; this report characterizes the form of retinol transported in plasma and tissues in selected fillies.

Treatment of tissues. Tissues were homogenized in a high-speed homogenizer (Ultraturrax; Janke-Kunkel KG, Stauffen i. Br., W. Germany) with $3 \mathrm{ml} 0.25 \mathrm{M}$-sucrose and 0.025 $\mathrm{M}$-potassium chloride/g tissue. Cytosol was prepared by spinning the homogenate at 105000 $g$ for $50 \mathrm{~min}$ in the Ti-50 rotor of a Beckman L3-50 centrifuge at $4^{\circ}$. Floating fat was sliced off and the clear cytosol collected.

Column chromatography. All stages were carried out in dim light and at $4^{\circ}$. Gel filtration was carried out on columns of Sepharose 6B and 2B (Pharmacia Fine Chemicals, Piscataway, NJ) in $50 \mathrm{~mm}$-Tris-hydrochloride, $\mathrm{pH} 8.0$. Some samples were brought to 3.0 $\mathrm{M}$-guanidine hydrochloride and chromatographed in the presence of $1.5 \mathrm{M}$-guanidine in the eluting buffer.

Ultracentrifugation. The density distribution of retinol and RPH was determined in cytosols, plasma and in various column fractions from Sepharose columns by ultracentrifugation at different sucrose densities, at $145000 \mathrm{~g}$ for $40 \mathrm{~h}$. Plasma samples were centrifuged at densities prepared with potassium bromide. Tubes were sliced in order to obtain top fractions.

$R P H$ activity. RPH activity was determined by incubation with retinyl $\left[{ }^{14} \mathrm{C}\right]$ palmitate prepared as described by Harrison et al. (1979) and free fatty acids formed were extracted as described by Belfrage \& Vaughan (1969).

Chemical methods. Retinol was separated from retinyl esters by alumina column chromatography, located in fractions from columns with a spectroflorimeter (Perkin Elmer Model No. 203) and levels in plasma and tissues determined as previously described 
Table 2. Concentrations $(\mu \mathrm{g} / \mathrm{g})$ of retinol and retinyl esters in the plasma and tissues of fillies given four levels of vitamin $A$

(Results are means of duplicate determination of tissues from the fillies for intracellular studies)

\begin{tabular}{|c|c|c|c|c|c|c|c|c|}
\hline \multirow[b]{2}{*}{ Group*... } & \multicolumn{2}{|c|}{ Mildly-deficient } & \multicolumn{2}{|c|}{ Control } & \multicolumn{2}{|c|}{ Mildly-intoxicated } & \multicolumn{2}{|c|}{ Severely-intoxicated } \\
\hline & $\begin{array}{l}\text { Retinyl } \\
\text { esters }\end{array}$ & Retinol & $\begin{array}{l}\text { Retinyl } \\
\text { esters }\end{array}$ & Retinol & $\begin{array}{l}\text { Retinyl } \\
\text { esters }\end{array}$ & Retinol & $\begin{array}{l}\text { Retinyl } \\
\text { esters }\end{array}$ & Retinol \\
\hline Plasma $(\mu \mathrm{g} / 1)$ & 38 & 50 & 4 & 307 & 2012 & 353 & 797 & 253 \\
\hline Liver & $2 \cdot 2$ & $2 \cdot 8$ & $76 \cdot 2$ & $13 \cdot 1$ & $1840 \cdot 0$ & $96 \cdot 4$ & $1330 \cdot 0$ & $57 \cdot 5$ \\
\hline Kidney & $0 \cdot 1$ & 0.1 & $1 \cdot 2$ & 0.8 & $6 \cdot 2$ & $1 \cdot 1$ & $52 \cdot 9$ & $92 \cdot 0$ \\
\hline Adrenal gland & 0.6 & $0 \cdot 3$ & $1 \cdot 5$ & $0 \cdot 3$ & $23 \cdot 8$ & $31 \cdot 2$ & $33 \cdot 8$ & $17 \cdot 8$ \\
\hline
\end{tabular}

(Donoghue et al. 1981). The linearity of the fluorescence was calibrated against chemical determinations and, where necessary, dilutions made. In addition, selected column fractions were checked by the chemical method to allow for differences in the quantum efficiencies of retinol bound to different proteins. Triglycerides, phospholipids (Sklan et al. 1975) and cholesterol were determined as previously described (Sklan \& Budowski, 1979).

\section{RESULTS}

Plasma and tissue concentrations of retinol and retinyl esters increased with vitamin A intake (Table 2).

Gel filtration of plasma from control animals on Sepharose 6B and determination of fluorescence and retinol, following extraction and alumina chromatography, in the fractions collected, showed the majority of retinol to be concentrated in the MW range $75000-80000$ (Fig. 1). Additional vitamin A fluorescence was observed at a MW of approximately $5 \times 10^{5}$, and this appeared to be mainly retinyl esters, whereas the lower MW peak consisted only of the retinol as determined by alumina chromatogiaphy. Ultracentrifugation of plasma from control animals showed that approximately $5 \%$ of total retinol was of hydrated density less than 1.21, whereas in intoxicated animals this proportion increased. Alumina chromatography showed the fraction of density less than 1.21 to be retinyl esters. Chromatography of plasma or of the concentrated 75000-80000 MW peak in the presence of guanidine resulted in almost complete disappearance of the original peak (MW $75000-80000$ ) and appearance of a new retinol containing peak with MW 20000 (Fig. 1).

In animals given high levels of vitamin $A$, the percentage of retinyl esters in the high $\mathrm{MW}$ peak increased to well over $50 \%$ of total retinol in severely-intoxicated animals.

Incubation of plasma or fractions of plasma from the Sepharose $6 \mathrm{~B}$ columns with retinyl $\left[{ }^{14} \mathrm{C}\right]$ palmitate resulted in hydrolysis of the order of $250 \mathrm{pmol}$ free fatty acid released $/ \mathrm{h}$ per $\mathrm{ml}$ plasma. Higher values were obtained with plasma column fractions from the Sepharose $6 \mathrm{~B}$ columns and the major hydrolytic activity was located in the region of MW 70000 .

Gel filtration of liver cytosol from a control animal determined that over $90 \%$ of total retinol (by fluorescent and chemical methods) was located close to the void volume of the Sepharose 6B column (Fig. 2), and on Sepharose 2B appeared to have a MW of approximately $2 \times 10^{6}$. This peak contained approximately $90 \%$ retinyl esters of total vitamin A and $48 \%$ lipids, which were predominantly triglycerides $(83 \%)$ and small amounts of cholesterol and phospholipids; it was associated with approximately $70 \%$ of total cytosol 


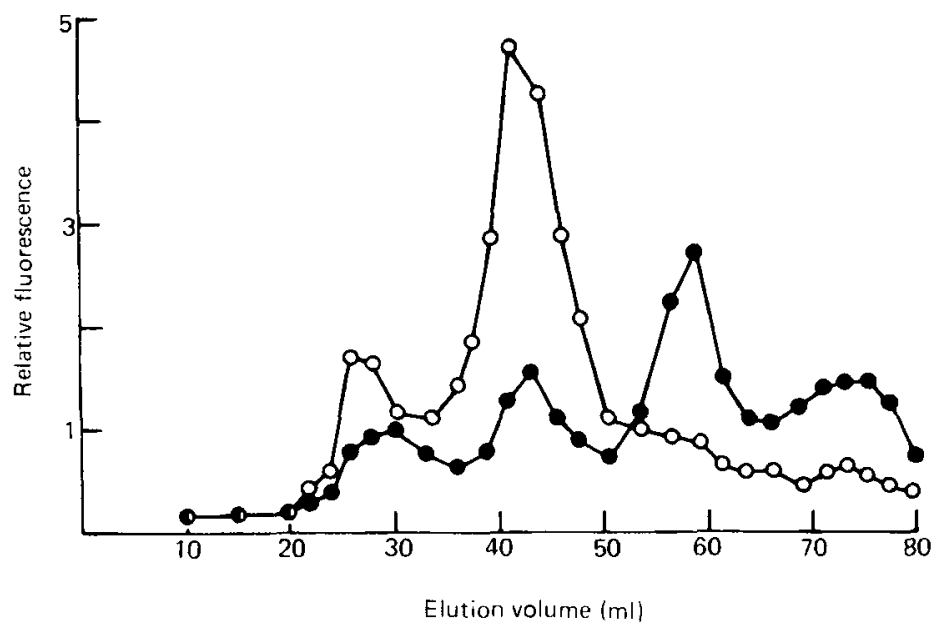

Fig. 1. Gel filtration of plasma from control $(\mathrm{O}-\mathrm{O})$ or toxic $(-\infty)$ animals treated with $3.0 \mathrm{M}$-guanidine and chromatographed with $1.5 \mathrm{M}$-guanidine on Sepharose $6 \mathrm{~B}(450 \times 17 \mathrm{~mm})$ in $50 \mathrm{~mm}$-tris hydrochloride $\mathrm{pH} 8.0$ plasma $(1.0 \mathrm{ml})$ was loaded on the columns and fractions of approximately $2.0 \mathrm{ml}$ were collected. For fluorescence determination excitation was set at $350 \mathrm{~nm}$ and emission determined at $470 \mathrm{~nm}$, and a spectrum run to ascertain presence of retinol. Columns were calibrated with blue dextran, thyroglobulin, apoferritin, phosphorylase B, albumin, ovalbumin, myoglobin, lysozyme and cytochrome $C$. The void volume of the column was $26.0 \mathrm{ml}$ and albumin eluted at $52.5 \mathrm{ml}$, myoglobin at $65.0 \mathrm{ml}$ and the salt volume was $77.0 \mathrm{ml}$.

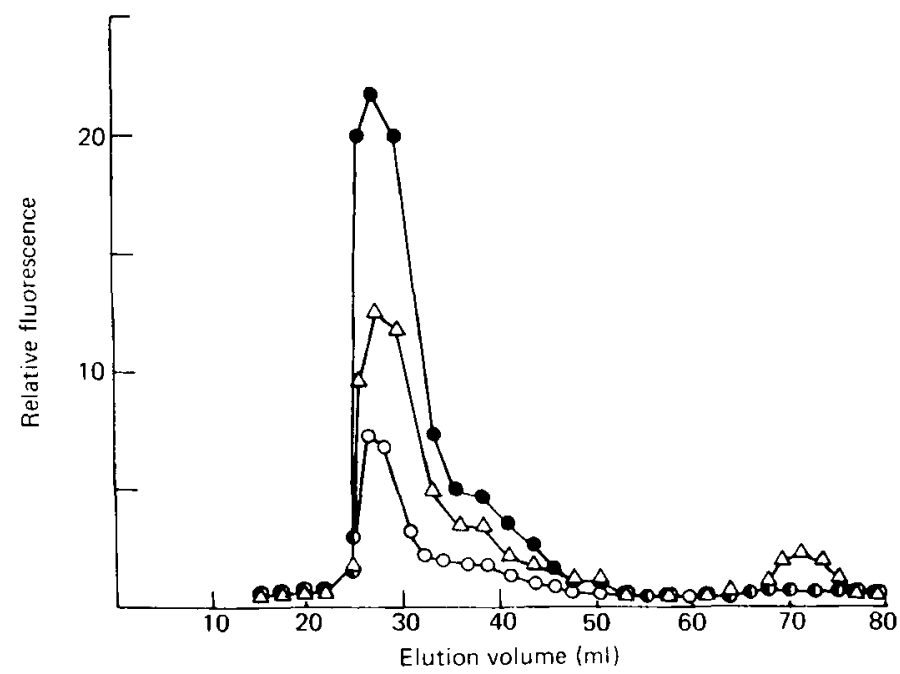

Fig. 2. Gel filtration of liver cytosol from control $(\mathrm{O}-\mathrm{O})$ or toxic (O-O) animals on Sepharose $6 \mathrm{~B}(450 \times 17 \mathrm{~mm})$ in $50 \mathrm{~mm}$-tris hydrochloride $\mathrm{pH} 8.0$. Cytosol $(2.0 \mathrm{ml})$ was loaded onto the column and fractions of approximately $2.0 \mathrm{ml}$ collected. The sample from the toxic liver was treated with 3.0 $\mathrm{M}$-guanidine and chromatographed in the presence of $1.5 \mathrm{M}$-guanidine $(\triangle-\triangle)$. Fluorescence was determined and column calibrated as described in Fig. 1. 
Table 3. Distribution of retinol fuorescence and retinyl palmitate hydrolase $(R P H)$ activity on ultracentrifugation of liver, kidney and adrenal cytosol of horses

(Results are means of two duplicate samples and cytosol levels set at $100 \%$ )

\begin{tabular}{|c|c|c|c|}
\hline Tissue & Density & $\begin{array}{c}\text { Fluorescence } \\
\text { in top layer } \\
(\%)\end{array}$ & $\begin{array}{c}\text { RPH } \\
\text { in top layer } \\
(\%)\end{array}$ \\
\hline \multicolumn{4}{|l|}{ Liver } \\
\hline & 1.063 & $4 \cdot 2$ & $2 \cdot 8$ \\
\hline & $1 \cdot 111$ & 85.8 & 83.6 \\
\hline & $1 \cdot 210$ & $107 \cdot 5$ & $95 \cdot 3$ \\
\hline & $1 \cdot 250$ & $103 \cdot 2$ & 94.4 \\
\hline \multicolumn{4}{|c|}{ Adrenal } \\
\hline & 1.063 & $1 \cdot 2$ & $3 \cdot 8$ \\
\hline & $1 \cdot 111$ & $66 \cdot 8$ & 56.5 \\
\hline & $1 \cdot 210$ & 96.0 & 78.4 \\
\hline & $1 \cdot 250$ & $98 \cdot 5$ & $84 \cdot 6$ \\
\hline \multicolumn{4}{|c|}{ Kidney } \\
\hline & $1 \cdot 063$ & 1.4 & $2 \cdot 7$ \\
\hline & $1 \cdot 111$ & $68 \cdot 3$ & 58.6 \\
\hline & $1 \cdot 210$ & 88.7 & $83 \cdot 2$ \\
\hline & $1 \cdot 250$ & 96.6 & 91.8 \\
\hline
\end{tabular}

Table 4. Distribution of retinol fluorescence and retinyl palmitate hydrolase $(R P H)$ activity in the retinol containing peaks isolated on Sapharose $2 B$ from kidney cytosol of horses

(Results are means of duplicate determinations; 1.25 top was set at $100 \%$ )

\begin{tabular}{|c|c|c|c|}
\hline Approximate $\mathrm{MW}$ & Density & $\begin{array}{c}\text { Fluorescence } \\
\text { in top layer } \\
(\%)\end{array}$ & $\begin{array}{c}\text { RPH } \\
\text { in top layer } \\
(\%)\end{array}$ \\
\hline \multirow[t]{5}{*}{$2 \times 10^{6}$} & & & \\
\hline & 1.063 & $2 \cdot 8$ & $4 \cdot 3$ \\
\hline & 1.090 & $\hat{35} \cdot 8$ & $43 \cdot 2$ \\
\hline & $1 \cdot 111$ & $86 \cdot 2$ & $84 \cdot 6$ \\
\hline & $1 \cdot 210$ & $113-2$ & $103 \cdot 8$ \\
\hline \multirow[t]{5}{*}{$2 \times 10^{5}$} & & & \\
\hline & 1.063 & $0 \cdot 8$ & 0.8 \\
\hline & 1.090 & $1 \cdot 3$ & 0.6 \\
\hline & $1 \cdot 111$ & $2 \cdot 3$ & 1.9 \\
\hline & $1 \cdot 210$ & $88 \cdot 7$ & $53 \cdot 4$ \\
\hline
\end{tabular}

RPH activity. The fluorescence spectrum exhibited excitation maximum at $350 \mathrm{~nm}$ and emission maximum at $470 \mathrm{~nm}$. Ultracentrifugation of this peak or of total liver cytosol (Tables 3,4 ) indicated that the density was in the range $1 \cdot 063-1 \cdot 111$, and that distribution of RPH activity paralleled that of retinol. In horses given the high level of vitamin A, concentrations of retinyl esters in this peak were enhanced, and a small shoulder with $\mathrm{MW}$ of approximately $2 \times 10^{5}$ appeared. Treatment of kidney cytosol in a similar manner (Fig. 3) showed that some $75 \%$ of total cytosol retinol was located in a similar peak which was close to the void volume of Sepharose $6 \mathrm{~B}$ but in the included volume on Sepharose $2 \mathrm{~B}$ and had a MW cf approximately $1.8 \times 10^{6}$. This peak contained $50 \%$ retinyl esters and some $42 \%$ lipids which were predominantly triglycerides. In addition, a second peak of retinol 


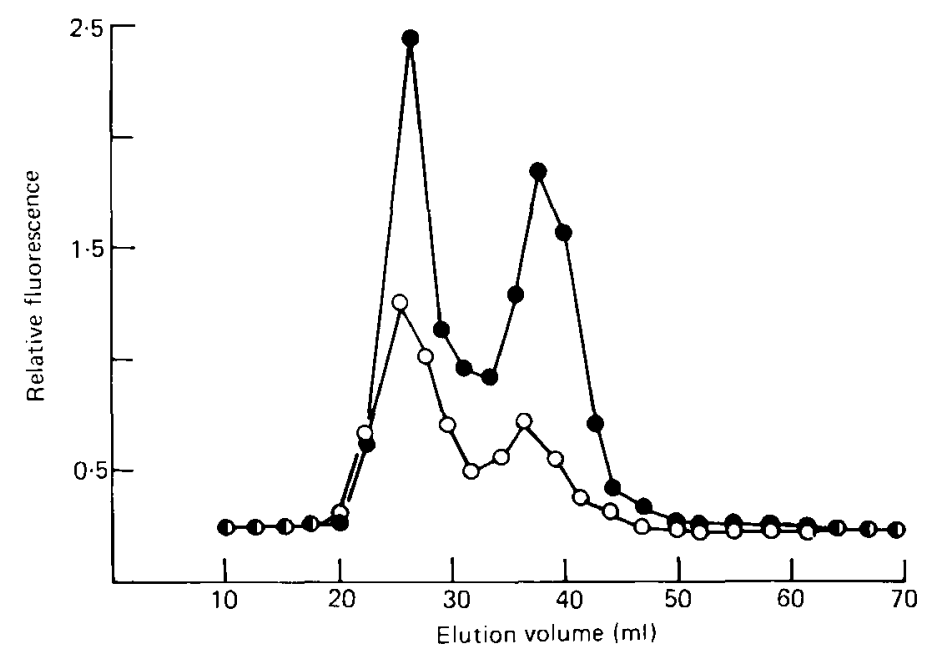

Fig. 3. Gel filtration of kidney cytosol from control $\left(\mathrm{O}_{-} \mathrm{O}\right)$ or toxic $\left(\mathrm{O}_{-}\right)$horses on Sepharose $6 \mathrm{~B}(430 \times 15 \mathrm{~mm})$. Cytosol $(1.0 \mathrm{ml})$ was loaded onto the column and fractions of about $2.3 \mathrm{ml}$ were collected. Fluorescence was determined as described in the legend to Fig. 1. The column was calibrated with standards as described in Fig. 1, and void volume was $20.0 \mathrm{ml}$, albumin eluted at $49.5 \mathrm{ml}$, myoglobin at $63.0 \mathrm{ml}$ and salt volume was $73.0 \mathrm{ml}$.

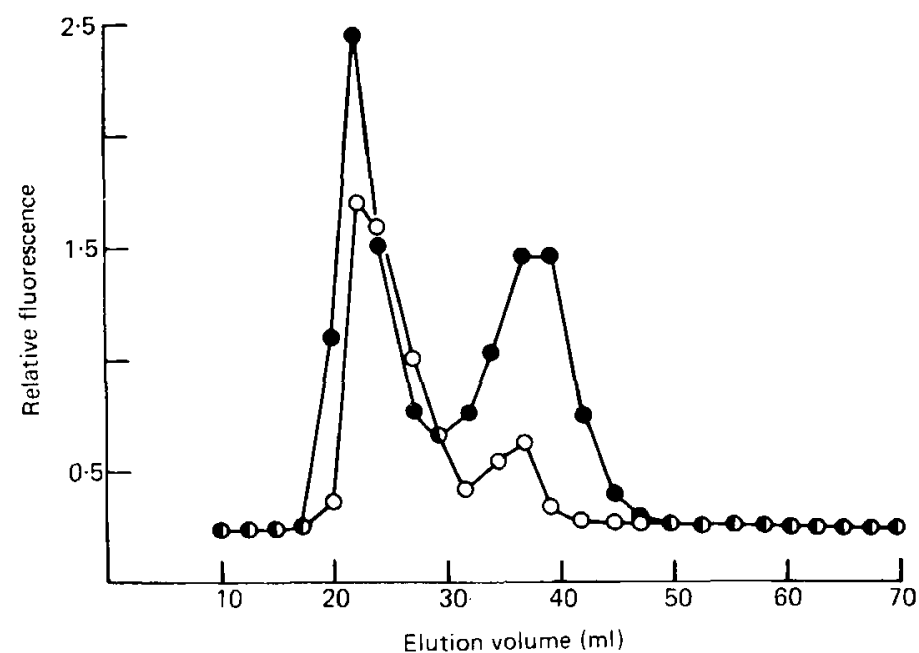

Fig. 4. Gel filtration of adrenal cytosol from control $(\mathrm{O}-\mathrm{O})$ or toxic $\left(\mathrm{O}_{-}\right)$horses on Sepharose $6 \mathrm{~B}(430 \times 15 \mathrm{~mm})$. Cytosol $(1.0 \mathrm{ml})$ was loaded and fractions of approximately $2.3 \mathrm{ml}$ were collected. Fluorescence was determined as described in the legend to Fig. 1, and column calibrated as described in Fig. 3.

was clearly observed with a $\mathrm{MW}$ in the range of $1.5-2 \times 10^{5}$. This fraction contained $30 \%$ retinyl esters, $70 \%$ retinol and approximately $20 \%$ lipid which was mainly triglycerides.

Both retinol-containing fractions were associated with RPH activity which was of the order of $2.0 \mu \mathrm{mol}$ free fatty acid released/h per $\mathrm{mg}$ protein in both peaks. Ultracentrifugation of cytosol (Table 3) and of the two fractions (Table 4) from control animals indicated that the density of the higher MW fraction was in the range 1.063-1.111, and of the lower MW fraction, approximately $1 \cdot 21$. The RPH activity was distributed similarly to the retinol. Increasing dietary intakes of vitamin A enhanced the lower MW fraction (Fig. 3) which contained over $40 \%$ of total vitamin $\mathrm{A}$ in severely intoxicated animals. 
Similar studies with adrenal cytosol revealed a similar pattern (Fig. 4) with two fractions of retinol containing proteins of $\mathrm{MW} 1.8 \times 10^{6}$ and $1.5-2 \times 10^{5}$; the percentage of retinyl esters of vitamin $A$ in the two fractions being 26 and 23 respectively, with lipid comprising 41 and $19 \%$ respectively. RPH activity was of similar magnitude per mg protein in both fractions and densities (Table 4) similar to those found in the kidney.

Chromatography of both retinol containing fractions isolated from cytosols on Sepharose $6 \mathrm{~B}$ in the presence of guanidine resulted in partial disappearance of the original peaks and appearance of retinol containing fractions at MW approximately 65000,42000 and 15000 (Fig. 2).

Gel filtration of cytosol from mildly-vitamin A-deficient fillies which had been preincubated with ${ }^{3} \mathrm{H}$ retinol showed distribution of the label similar to the retinol distribution in normal animals with two peaks apparent in kidney and adrenal cytosol.

\section{DISCUSSION}

Our results indicate that the transport of retinol in the plasma of the equine is similar to that described for other species (Muto et al. 1973; Glover et al. 1974). Retinol is complexed to a protein with MW of approximately 20000 , presumably RBP, which is, in turn, complexed with prealbumin yielding a complex with $\mathrm{MW}$ in the range $75000-80000$. In the rat, the RBP-prealbumin complex has a MW of 75000 and can be dissociated by reducing the ionic strength (Petersen, 1971; Muto \& Goodman, 1972) or by guanidine treatment (McGuire \& Chytil, 1980). Most of the plasma retinol in horses with a normal vitamin A intake was RBP-prealbumin bound with the remainder in the form of lipoprotein-bound retinyl esters. In animals with a high vitamin A intake, levels of retinyl esters increased in lipoproteins of hydrated density less than 1.21 as has been previously described in the hypervitaminotic A rat (Mallia et al. 1975). The in vitro hydrolysis of retinyl esters in the plasma may be due to the action of lipoprotein lipase which would fit the MW region where hydrolysis was found (Augustin et al. 1978). The significance of the release of non-RBP-bound retinol in the plasma is unknown and could become significant in intoxicated animals.

We also found a retinyl ester-containing lipoprotein in equine tissues. The involvement of such an aggregate in retinol transport in rats has been previously suggested by Heller (1976, 1979). Equine liver contains an aggregate with MW approximately $2 \times 10^{6}$, with a hydrated density of $1.063-1.09$ and containing approximately $80 \%$ triglycerides. This aggregate is associated with RPH activity. Guanidine treatment releases a protein-binding retinol, but not retinyl esters, with a MW of approximately 15000 . In rat liver, it has been found by immunological means that this is intracellular retinol binding protein (Sklan, Blaner, Adachi, Smith \& Goodman, unpublished results).

The presence of two retinol-containing aggregates in kidney and adrenal cytosol may be of metabolic significance. The major, higher MW aggregate was similar to that observed in the liver although there was marginally-less lipid present and the MW was slightly smaller. The second lower MW lipoprotein contained only $20 \%$ lipids and had a MW of $1.7 \times 10^{5}$. This aggregate also was associated with RPH activity, and guanidine treatment released a $15000 \mathrm{MW}$ retinol-binding fraction. The nature of this $1.7 \times 10^{5} \mathrm{MW}$ fraction is intriguing; the presence of a higher proportion of free retinol may indicate that this is a stage in the release of retinol from intracellular retinol-binding protein. Furthermore, almost all the vitamin $\mathrm{A}$ is in the form of retinyl esters in the liver, whereas less than half the retinol is esterified in the kidney and adrenal gland. Thus, the functions of the lipid-protein aggregates may represent successive stages in the transport of retinol and the hydrolysis of retinyl esters to retinol for binding to the intracellular binding protein.

Intracellular retinol transport in the equine liver appears to be similar to that reported 
in the rat, with a high $\mathrm{MW}$ lipoprotein playing a role. The two lipid-protein aggregates which we found in equine kidney and adrenal glands may be of particular significance in animals with high vitamin $\mathrm{A}$ intakes.

This study was funded in part by the Commonwealth of Pennsylvania Department of Agriculture, Biomedical Research Support Program Grant 5 S07 RR 5464, and by BASF, Ludwigshafen.

\section{REFERENCES}

Augustin, J., Freeze, H., Tejada, P. \& Brown, W. V. (1978). J. biol. Chem. 253, 2912.

Belfrage, P. \& Vaughan, M. (1969). J. Lipid Res. 10, 341.

Chen, C. C. \& Heller, J. (1979). Archs Biochem. Biophys. 198, 572.

Donoghue, S., Kronfeld, D. S., Berkowitz, S. J. \& Copp, R. L. (1981). J. Nutr. 111, 365.

Glover, J., Jay, C. \& White, G. H. (1974). Vitam. Horm. 32, 215.

Harrison, E. H., Smith, J. E. \& Goodman, D. S. (1979). J. Lipid Res. $20,760$.

Heller, J. (1976). J. biol. Chem. 251, 2952.

Heller, J. (1979). Archs Biochem. Biophys. 198, 562.

McGuire, B. W. \& Chytil, F. (1980). Biochim. biophys. Acta. 621, 324.

Mallia, A. K., Smith, J. E. \& Goodman, D. S. (1975). J. Lipid Res. 16, 180.

Muto, Y. \& Goodman, D. S. (1972). J. biol. Chem. 247, 2553.

Muto, Y., Smith, F. R. \& Goodman, D. S. (1973). J. Lipid Res. 14, 525.

Ong, D. E. \& Chytil, F. (1978). J. biol. Chem. 254, 8733.

Petersen, P. A. (1971). J. biol. Chem. 246, 34.

Ross, A. C., Takahashi, Y. I. \& Goodman, D. S. (1978). J. biol. Chem. 253, 6591.

Sklan, D. \& Budowski, P. (1979). Lipids 14, 386.

Sklan, D., Hurwitz, S., Budowski, P. \& Ascarelli, I. (1975), J. Nutr. 105, 57.

Smith, J. E. \& Goodman, D. S. (1979). Fedn Proc. Fedn Am. Socs exp. Biol. 38, 60. 